\title{
Prescription medication nonadherence associated with food insecurity: a population-based cross-sectional study
}

\author{
Fei Men PhD, Craig Gundersen PhD, Marcelo L. Urquia PhD, Valerie Tarasuk PhD
}

\section{Abstract}

Background: Food insecurity, defined as inadequate access to food owing to financial constraints, has been associated with poor disease management. Because cost-related nonadherence to prescription drugs is a possible explanation for such association, we examined the link between food insecurity and cost-related medication nonadherence in Canada.

Methods: Drawing on data for adult respondents (age $\geq 18 \mathrm{yr}$ ) who participated in the Canadian Community Health Survey 2016 Rapid Response module on prescription medication use, we assessed the association between household food insecurity and costrelated nonadherence to prescription drugs in the previous 12 months. We further examined the self-perceived health consequences of cost-related nonadherence among nonadherents. We applied Poisson models with bootstrap weights adjusting for sociodemographic characteristics.

Results: Of the 11172 respondents in our sample, 930 (8.3\%) reported cost-related nonadherence. Food insecurity affected $10.5 \%$ (95\% confidence interval [Cl] $9.1 \%$ to $11.8 \%)$ of adherents and $47.9 \%(95 \% \mathrm{Cl} 38.1 \%$ to $57.7 \%)$ of nonadherents. After adjustment for confounders, moderate and severe food insecurity were associated with $3.83(95 \% \mathrm{Cl} 2.44$ to 6.03$)$ and 5.05 (95\% $\mathrm{Cl} 3.27$ to 7.81) times higher prevalence of cost-related nonadherence, respectively, relative to food security. Despite being associated with lower probability of cost-related nonadherence, having drug insurance did not change the relation between food insecurity and costrelated nonadherence ( $p>0.1$ for all interactions). Severe food insecurity was correlated with higher prevalence of health deterioration and greater use of health care services as perceived consequences of cost-related nonadherence ( $p<0.01$ for both).

Interpretation: Food-insecure adults in Canada have a higher likelihood of cost-related nonadherence to prescription medications than their food-secure counterparts, which may constitute a burden on their health and lead to greater use of health care services.

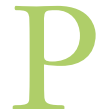
rescription drugs in Canada are covered by a patchwork of public and private insurance. Social assistance recipients are generally covered by public insurance, as are most older adults and Aboriginal people, ${ }^{1}$ but most working-age adults rely on private insurance linked to their employment. ${ }^{2}$ For those with no other drug coverage, provincial governments offer catastrophic insurance that caps the out-of-pocket expenses to a fixed amount or percentage of income. ${ }^{3}$ Yet there are over 4 million Canadians not enrolled in a drug insurance plan. ${ }^{4}$ Moreover, deductibles, coinsurance and copayment are common out-of-pocket expenses in both public and private insurance programs. ${ }^{1}$ Law and colleagues ${ }^{5}$ conducted a populationbased cross-sectional survey to study the consequences of patient charges for prescription drugs in Canada in 2016. They estimated that cost-related medication nonadherence - delaying, reducing or skipping prescribed medication owing to cost - was experienced by $8.2 \%$ of Canadians with a prescription in the previous year. The rate was especially high for young adults, lower-income households and those without drug insurance. An estimated $4.7 \%$ of
Canadians cut other expenses to afford prescription drugs, with half of them reducing food spending, ${ }^{5}$ which suggests a link to household food insecurity.

Food insecurity, defined as inadequate access to food owing to financial constraints, affected $12.6 \%$ of Canadian households in 2012. ${ }^{6}$ It has been linked to increased prevalence of chronic conditions, ${ }^{7}$ poorer disease management, ${ }^{8-10}$ greater use of health care services ${ }^{11,12}$ and higher mortality risk in Canada. ${ }^{13}$ The mechanisms by which food insecurity affects health remain largely unknown, but cost-related nonadherence is one potential pathway. Financially vulnerable households often make trade-offs among necessities such as food and medication. ${ }^{14-16}$ Depending on the degree of financial

\section{Competing interests: None declared.}

This article has been peer reviewed.

Correspondence to: Fei Men, fei.men@utoronto.ca

CMAJ Open 2019. DOI:10.9778/cmajo.20190075 
constraint and factors such as spending priorities, households may sacrifice spending on medications to purchase needed food or vice versa, or they may compromise spending in both categories. ${ }^{14-16}$ The accumulation of disadvantages has been documented in Canada and the United States, with foodinsecure households often simultaneously experiencing multiple material and financial hardships, including high out-ofpocket medical expenses. ${ }^{17-20}$ Population-based studies have also associated food insecurity with cost-related nonadherence among US adults; ${ }^{16,21,22}$ however, little is known about this relation in Canada despite its plausibility.

Building on the work of Law and colleagues, ${ }^{5}$ we used cross-sectional data to test the hypothesis that cost-related medication nonadherence increases with severity of food insecurity among Canadian adults. Because poor adherence to medications may compromise food-insecure patients' management of chronic conditions and increase their risk for more serious health outcomes, we also explored the relation of food insecurity with forgoing drugs for chronic conditions and perceived health consequences of cost-related nonadherence.

\section{Methods}

\section{Data sources}

The Canadian Community Health Survey is a cross-sectional telephone survey conducted annually by Statistics Canada representing $98 \%$ of the Canadian community-dwelling population aged 12 years or more. Since 2015, samples of 65000 households per year have been drawn from geographic area and Canadian Child Tax Benefit frames, with 1 household member selected randomly to answer questions. From January to June 2016, a rapid response component on prescription drug use was administered to respondents in the 10 provinces, with a person-level response rate of $85.3 \% .^{23}$ Household food insecurity was also assessed in the survey; however, Ontario, Newfoundland and Labrador and the Yukon Territory opted out of this measurement in 2016.

\section{Setting}

Our sample included households that participated in both the rapid response component and the food security module. We excluded the territories as well as respondents interviewed after June 2016 (who therefore did not participate in the rapid response component). We also excluded respondents with missing food security status, including all those from Ontario and Newfoundland and Labrador. Of the remaining respondents, we retained those aged 18 years or more who had at least 1 drug prescription in the previous year and no missing data on cost-related nonadherence.

\section{Outcomes}

Our primary outcome was cost-related medication nonadherence conditional on receiving a drug prescription. The outcome derived from 2 survey questions regarding 1) not filling or collecting a drug prescription or skipping doses in the previous 12 months because of cost and 2) reducing dosage or delaying filling in the previous 12 months because of cost (see
Appendix 1, available at www.cmajopen.ca/content/7/3/E590/ suppl/DC1, for questionnaire). A response of "yes" to either question constituted nonadherence.

To explore the possibility that cost-related nonadherence mediates the linkage between food insecurity and health, we also examined nonadherence to drugs for major chronic conditions and self-perceived health consequences of cost-related nonadherence as secondary outcomes. We created 3 binary indicators for the nonadherent subsample: 1) whether the unafforded drug was for cancer, heart disease, high cholesterol level, high blood pressure, asthma, chronic obstructive pulmonary disease, diabetes, gut problems, arthritis, chronic pain or mental disorders, 2) whether the respondent perceived that his or her health had worsened as a consequence of inability to afford prescription medications and 3) whether the respondent reported visiting a doctor, being admitted to hospital or going to the emergency department because of costrelated medication nonadherence.

\section{Exposure}

Our exposure of interest was household food insecurity. Based on the number of affirmative answers to 18 questions on a household's access to food over the previous 12 months (Appendix 2, available at www.cmajopen.ca/content/7/3/ E590/suppl/DC1), we categorized households as "food secure," "marginally food insecure," "moderately food insecure" or "severely food insecure" (Supplementary Table S1, Appendix 3, available at www.cmajopen.ca/content/7/3/E590/ suppl/DC1).

We adjusted for confounding factors associated with costrelated nonadherence in Canada, ${ }^{24}$ including household income, prescription insurance, age and province of residence. We also controlled for factors associated with Canadian households' food insecurity in past research, including sex, Aboriginal identity, housing tenure and household type. . $^{7,25}$ Because regimen complexity has been found to be a key determinant of drug adherence, ${ }^{14,27}$ we further controlled for number of different medications prescribed in the previous year in our models. We tagged missing values with a separate category for the covariates on drug insurance, Aboriginal status, housing tenure and household type. Statistics Canada imputed income for the $11.7 \%$ of the sample for whom it was missing; we flagged the imputed income with a dichotomous indicator.

\section{Statistical analysis}

We described the sample characteristics with unweighted counts and weighted proportions by medication nonadherence status. We then fitted weighted Poisson regressions on cost-related nonadherence, analyzing the 2 relevant outcomes separately and also collapsing them into a single indicator. Because medication insurance may reduce out-of-pocket drug expenses and increase disposable income for food, we stratified the sample by insurance status and tested whether insurance moderated the association between food insecurity and cost-related nonadherence. We estimated average predicted probabilities (i.e., sample mean of individual probabilities) for those with and without drug insurance, adjusting for 
confounders. Last, we restricted the sample to adults who reported cost-related nonadherence and regressed the secondary outcomes on the same set of covariates used in the primary analyses. With the exception of household income, for which Statistics Canada imputed missing values, we did not impute missing values for covariates in our main analyses. However, to ensure the results were not driven by missing values, we experimented with chained multiple imputation for the 750 respondents with missing values for drug insurance, Aboriginal status, housing tenure or household type. We performed all analyses in Stata SE 15.1 (StataCorp), applying 1000-replication bootstrap weights from the Canadian Community Health Survey.

\section{Ethics approval}

We obtained ethics approval from the University of Toronto Health Sciences Research Ethics Board.

\section{Results}

Our analytic sample consisted of 11172 adults with prescriptions from 8 provinces (Figure 1). Of the 11172,737 reported not filling or collecting drug prescriptions or skip-

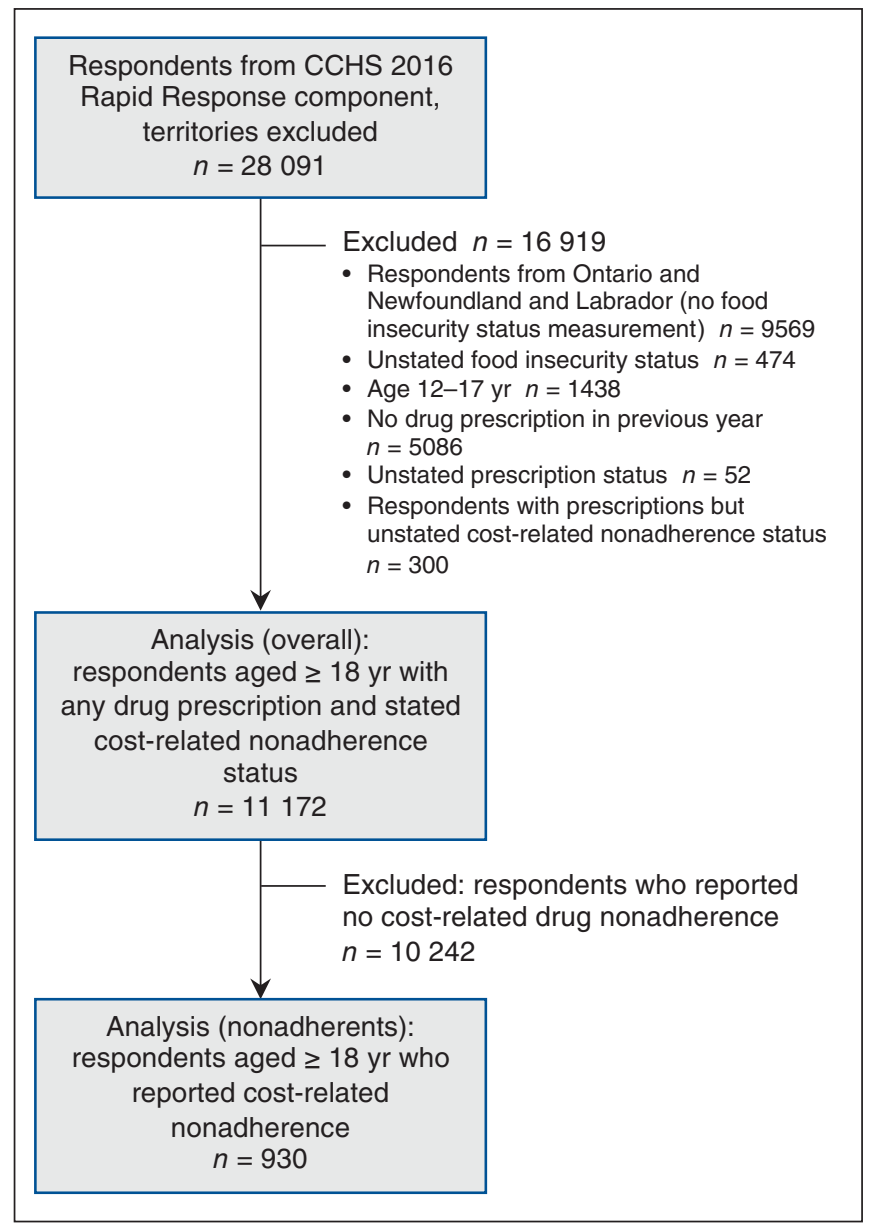

Figure 1: Flow diagram showing sample selection. Note: $\mathrm{CCHS}=$ Canadian Community Health Survey. ping doses because of cost, and 748 reported reducing dosage or delaying filling of prescriptions because of cost. Taken together, 930 respondents $(8.3 \%)$ reported cost-related nonadherence, of whom 564 reported having drug insurance (Table 1). Compared to adherents, nonadherents were more likely to be female, young, renters, of Aboriginal identity and from lower-income households, and to report no drug insurance (Table 1). Food insecurity was experienced by $10.5 \%$ (95\% confidence interval [CI] $9.1 \%$ to $11.8 \%$ ) of adherents and $47.9 \%$ (95\% CI $38.1 \%$ to $57.7 \%$ ) of nonadherents. Costrelated nonadherence was reported by $4.9 \%$ (95\% CI $4.1 \%$ to $5.6 \%)$ of food-secure respondents and by $13.2 \%$ (95\% CI $7.6 \%$ to $18.8 \%$ ), $29.4 \%$ (95\% CI $23.3 \%$ to $35.6 \%$ ) and $47.1 \%$ (95\% CI $40.4 \%$ to $53.8 \%$ ) of those from marginally, moderately and severely food-insecure households, respectively. Over half of nonadherents $(61.2 \%, 95 \%$ CI $56.0 \%$ to $66.3 \%)$ could not afford drugs for their chronic conditions, $42.7 \%$ (95\% CI $38.2 \%$ to $47.3 \%$ ) felt their health condition had worsened as a result of cost-related nonadherence, and $19.7 \%$ (95\% CI $15.1 \%$ to $24.3 \%$ ) reported greater use of health care services as a result of cost-related nonadherence.

The association between severity of food insecurity and cost-related nonadherence was graded (Table 2, Supplementary Table S2, Appendix 3). After adjustment for sociodemographic confounders, cost-related nonadherence was 1.82 (95\% CI 1.00 to 3.31 ), 3.83 (95\% CI 2.44 to 6.03 ) and 5.05 (95\% CI 3.27 to 7.81 ) times more prevalent among adults from marginally, moderately and severely food-insecure households, respectively, relative to their food-secure counterparts. Translated into predicted probability, the figure was 0.05 (95\% CI 0.04 to 0.07 ) for food-secure adults and 0.10 (95\% CI 0.06 to 0.14 ), 0.20 (95\% CI 0.15 to 0.25 ) and 0.27 (95\% CI 0.21 to 0.33 ) for marginally, moderately and severely food-insecure adults, respectively. Missing values for covariates barely influenced the results: estimates from the multiple imputation yielded prevalence ratios (PRs) of 1.84 (95\% CI 1.28 to 2.66 ), 3.75 (95\% CI 2.84 to 4.96 ) and 4.99 (95\% CI 3.79 to 6.58 ) for marginally, moderately and severely foodinsecure adults, respectively. The association with food insecurity was qualitatively the same for not filling prescriptions or skipping doses versus reducing dosage or delaying filling prescriptions except that the former was not associated with marginal food insecurity $(p>0.1)$. The association of food insecurity with cost-related nonadherence was similar for respondents with and without drug insurance; however, the association with marginal food insecurity was significant only among insured respondents (Table 2). Although the probability of nonadherence was mostly lower for insured versus uninsured respondents across food insecurity levels (Figure 2), insurance did not change the correlation between food insecurity and nonadherence (interaction $p>0.1$ for all).

Among nonadherents, severe food insecurity was associated with higher nonadherence to drugs for chronic conditions (PR 1.42, 95\% CI 1.11 to 1.79 ), as well as perceived health deterioration (PR 1.63, 95\% CI 1.18 to 2.24) and increased use of health care services (PR 2.86, 95\% CI 1.72 to 4.74 ) because of cost-related nonadherence (Table 3). Moderate 


\begin{tabular}{|c|c|c|}
\hline \multirow[b]{2}{*}{ Characteristic } & \multicolumn{2}{|c|}{$\%$ of population* $(95 \% \mathrm{Cl})$} \\
\hline & $\begin{array}{c}\text { Adherents } \\
n=10242 \dagger\end{array}$ & $\begin{array}{c}\text { Nonadherents } \\
n=930 \dagger\end{array}$ \\
\hline \multicolumn{3}{|l|}{ Household food insecurity } \\
\hline Food secure & 89.5 (88.2 to 90.9$)$ & 52.1 (42.3 to 61.9$)$ \\
\hline Marginally food insecure & $3.7(3.1$ to 4.3$)$ & $6.4(3.3$ to 9.4$)$ \\
\hline Moderately food insecure & $4.9(4.3$ to 5.6$)$ & 23.3 (19.1 to 27.4$)$ \\
\hline Severely food insecure & 1.8 (1.0 to 2.7$)$ & 18.3 (12.4 to 24.2$)$ \\
\hline Any food insecurity & $10.5(9.1$ to 11.8$)$ & 47.9 (38.1 to 57.7$)$ \\
\hline Female sex & 55.8 (51.4 to 60.3$)$ & 65.3 (59.8 to 70.9$)$ \\
\hline \multicolumn{3}{|l|}{ Age quartile (yr) } \\
\hline 1st $(18-37)$ & 26.7 (19.9 to 33.6$)$ & 44.6 (34.9 to 54.3$)$ \\
\hline 2nd (38-54) & $27.0(21.5$ to 32.5$)$ & $27.2(23.0$ to 31.3$)$ \\
\hline 3rd (55-67) & 26.5 (24.8 to 28.3$)$ & $16.4(11.3$ to 21.6$)$ \\
\hline 4th $(68-98)$ & 19.7 (8.8 to 30.6$)$ & 11.8 (5.1 to 18.5$)$ \\
\hline Older adults $(65-98)$ & 25.7 (12.3 to 39.2$)$ & 14.9 (6.4 to 23.5$)$ \\
\hline \multicolumn{3}{|l|}{ Household income quartile (\$‡) } \\
\hline 1st $(\leq 37000)$ & 18.0 (5.9 to 30.2$)$ & $30.3(17.2$ to 43.5$)$ \\
\hline 2nd (37 001-69 000) & 23.1 (19.0 to 27.2$)$ & 30.6 (25.8 to 35.3$)$ \\
\hline 3rd (69 001-118 000) & 27.1 (23.1 to 31.0$)$ & $23.7(15.5$ to 31.9$)$ \\
\hline 4th $(>118000)$ & 31.8 (19.5 to 44.2$)$ & 15.4 (7.7 to 23.1$)$ \\
\hline Statistics Canada imputed income & 11.5 (10.0 to 13.0$)$ & $15.2(10.1$ to 20.4$)$ \\
\hline \multicolumn{3}{|l|}{ Aboriginal status } \\
\hline Non-Aboriginal & 95.7 (95.1 to 96.3$)$ & 90.0 (86.6 to 93.5$)$ \\
\hline Aboriginal & $3.9(3.3$ to 4.4$)$ & $9.3(5.9$ to 12.8$)$ \\
\hline Missing & $0.4(0.2$ to 0.6$)$ & 0.7 (0.1 to 1.2$)$ \\
\hline \multicolumn{3}{|l|}{ Housing tenure } \\
\hline Renter & 24.7 (15.6 to 33.7$)$ & 46.2 (38.9 to 53.5$)$ \\
\hline Homeowner & $75.3(66.2$ to 84.3$)$ & $53.7(46.3$ to 61.0$)$ \\
\hline Missing & $0.1(0.0$ to 0.1$)$ & $0.1(-0.2$ to 0.5$)$ \\
\hline \multicolumn{3}{|l|}{ Household type } \\
\hline Couple with children & 34.7 (14.3 to 55.1$)$ & $31.8(12.5$ to 51.0$)$ \\
\hline Couple without children & 35.8 (30.4 to 41.1$)$ & 22.1 (15.9 to 28.3 ) \\
\hline Lone parents & $7.4(6.3$ to 8.4$)$ & $14.3(10.9$ to 17.7$)$ \\
\hline Other & $21.8(-3.5$ to 47.1$)$ & 30.3 (5.5 to 55.2$)$ \\
\hline Missing & $0.4(0.1$ to 0.7$)$ & $1.5(-0.1$ to 3.2$)$ \\
\hline \multicolumn{3}{|l|}{ Province of residence } \\
\hline British Columbia & 19.8 (18.2 to 21.5$)$ & 32.5 (27.8 to 37.2$)$ \\
\hline Alberta & $19.0(16.1$ to 21.9$)$ & 20.9 (15.1 to 26.7$)$ \\
\hline Saskatchewan & $5.1(4.6$ to 5.6$)$ & $4.8(3.1-6.4)$ \\
\hline Manitoba & $5.7(5.3$ to 6.0$)$ & $6.0(3.8$ to 8.1$)$ \\
\hline Quebec & 40.7 (37.2 to 44.3$)$ & $26.2(19.8$ to 32.5$)$ \\
\hline Atlantic provinces§ & 9.7 (9.1 to 10.2$)$ & $9.7(6.7$ to 12.7$)$ \\
\hline \multicolumn{3}{|l|}{ Prescription drug insurance } \\
\hline Uninsured & $13.8(12.7$ to 14.9$)$ & 32.1 (27.7 to 36.4$)$ \\
\hline Insured & 83.6 (81.7 to 85.5$)$ & 63.8 (59.6 to 68.0$)$ \\
\hline Missing & 2.6 (1.5 to 3.7$)$ & $4.1(2.4$ to 5.9$)$ \\
\hline \multicolumn{3}{|l|}{ No. of medications prescribed } \\
\hline 1 & $51.4(43.7$ to 59.1$)$ & 38.7 (34.2 to 43.2 ) \\
\hline 2 & 27.2 (25.0 to 29.3 ) & 31.3 (26.7 to 35.9$)$ \\
\hline$\geq 3$ & 21.4 (15.4 to 27.4$)$ & 30.0 (25.5 to 34.5$)$ \\
\hline \multicolumn{3}{|c|}{$\begin{array}{l}\text { Note: } \mathrm{Cl}=\text { confidence interval. } \\
\text { 'Weighted by } 1000 \text {-replication bootstrap weights from the Canadian Community Health Survey } 2016 . \\
\text { †Unweighted counts from the sample. } \\
\text { †Rounded to the nearest } \$ 1000 \text { to protect respondents' identity. } \\
\text { §Prince Edward Island, Nova Scotia and New Brunswick. }\end{array}$} \\
\hline
\end{tabular}




\begin{tabular}{|c|c|c|c|c|c|}
\hline \multirow[b]{3}{*}{$\begin{array}{l}\text { Household food } \\
\text { insecurity status }\end{array}$} & \multicolumn{5}{|c|}{ Consequence; prevalence ratio $(95 \% \mathrm{Cl})$} \\
\hline & \multirow{2}{*}{$\begin{array}{l}\text { Not filling } \\
\text { prescription or } \\
\text { skipping doses } \\
n=11178 \dagger\end{array}$} & \multirow{2}{*}{$\begin{array}{l}\text { Reducing dosage } \\
\text { or delaying filling } \\
\text { prescription } \\
n=11466 \dagger\end{array}$} & \multicolumn{3}{|c|}{ Nonadherence } \\
\hline & & & $\begin{array}{c}\text { Overall sample } \\
n=11172 \dagger\end{array}$ & $\begin{array}{l}\text { Respondents } \\
\text { without insurance } \\
\quad n=1897 \dagger\end{array}$ & $\begin{array}{l}\text { Respondents with } \\
\text { insurance } \\
n=8943 \dagger\end{array}$ \\
\hline Food secure & 1.00 (ref) & 1.00 (ref) & 1.00 (ref) & 1.00 (ref) & 1.00 (ref) \\
\hline $\begin{array}{l}\text { Marginally food } \\
\text { insecure }\end{array}$ & 1.48 (0.84 to 2.62$)$ & $2.22(1.14$ to 4.35$)$ & $1.82(1.00$ to 3.31$)$ & $1.20(0.49$ to 2.93$)$ & 2.27 (1.24 to 4.14$)$ \\
\hline $\begin{array}{l}\text { Moderately food } \\
\text { insecure }\end{array}$ & $3.30(2.08$ to 5.24$)$ & 4.58 (2.74 to 7.67$)$ & 3.83 (2.44 to 6.03$)$ & $3.50(2.16$ to 5.66$)$ & 4.27 (2.65 to 6.88$)$ \\
\hline $\begin{array}{l}\text { Severely food } \\
\text { insecure }\end{array}$ & 4.77 (3.01 to 7.55$)$ & $6.58(4.02$ to 10.77$)$ & 5.05 (3.27 to 7.81$)$ & 5.18 (3.67 to 7.30$)$ & $5.20(3.24$ to 8.34$)$ \\
\hline \multicolumn{6}{|c|}{$\begin{array}{l}\text { Note: } \mathrm{Cl}=\text { confidence interval, ref }=\text { reference category. } \\
\text { *From Poisson regression with bootstrapped standard error. All models were adjusted for household income, imputed income, sex, age, Aboriginal status, housing tenure, } \\
\text { household type, province, drug insurance status (missing for } 332 \text { respondents) and number of different drugs prescribed. } \\
\text { †Unweighted number of observations. }\end{array}$} \\
\hline
\end{tabular}

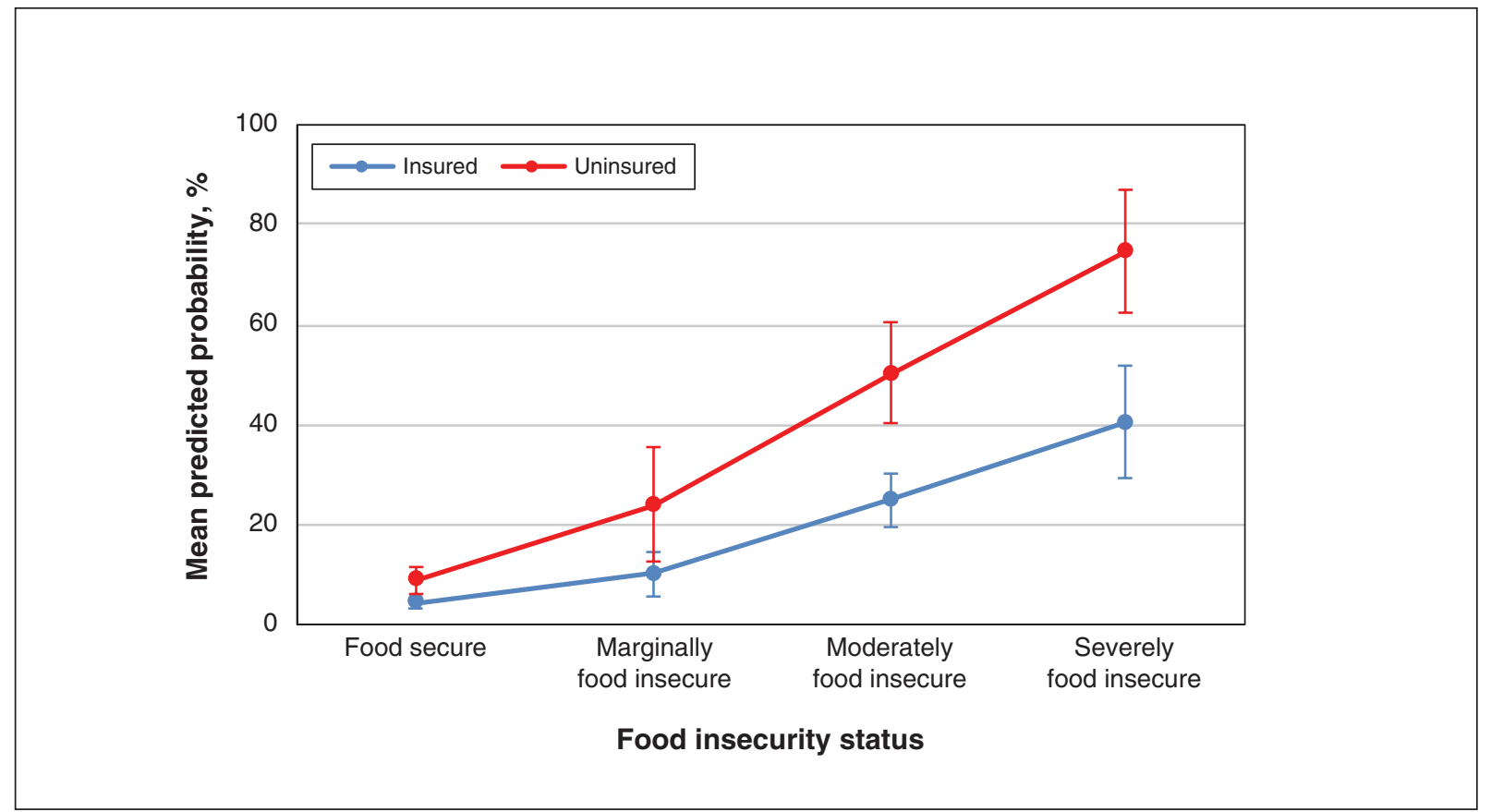

Figure 2: Mean predicted probability of cost-related medication nonadherence (sample mean of individual predicted probabilities) for respondents with and without prescription drug insurance by household food insecurity status; 332 respondents with missing insurance status were excluded from the analysis. Poisson regression with bootstrapped standard error was used, adjusting for household income, imputed income, income source, sex, age, Aboriginal status, housing tenure, household type, province of residence and number of different drugs prescribed. Error bars represent $95 \%$ confidence interval.

food insecurity was associated with higher prevalence of costrelated nonadherence to drugs for chronic conditions (PR $1.28,95 \%$ CI 1.07 to 1.53$)$ and worse health owing to unaffordable prescriptions (PR 1.48, 95\% CI 1.11 to 1.98 ) but not greater use of health care services (PR 1.66, 95\% CI 0.97 to 2.85). There was no statistically significant association with marginal food insecurity.

\section{Interpretation}

Despite the removal of adolescents and 2 provinces from our sample, the prevalence of cost-related nonadherence to prescription drugs was virtually the same as that reported by Law and colleagues ${ }^{5}$ using the same data. Similar to findings from US-based studies, ${ }^{16,21,22}$ after adjustment for confounders, we 


\begin{tabular}{|c|c|c|c|}
\hline \multirow[b]{2}{*}{$\begin{array}{l}\text { Household food } \\
\text { insecurity status }\end{array}$} & \multicolumn{3}{|c|}{ Characteristic/consequence; prevalence ratio $(95 \% \mathrm{Cl})$} \\
\hline & $\begin{array}{l}\text { Nonadherence for } \\
\text { chronic conditions } \\
\quad n=902 \dagger\end{array}$ & $\begin{array}{c}\text { Worse health } \\
n=890 \dagger\end{array}$ & $\begin{array}{c}\text { Greater use of health } \\
\text { care services } \\
n=909 \dagger\end{array}$ \\
\hline Food secure & 1.00 (ref) & 1.00 (ref) & 1.00 (ref) \\
\hline $\begin{array}{l}\text { Marginally food } \\
\text { insecure }\end{array}$ & $1.03(0.75$ to 1.40$)$ & $1.31(0.88$ to 1.96$)$ & $1.65(0.77$ to 3.54$)$ \\
\hline $\begin{array}{l}\text { Moderately food } \\
\text { insecure }\end{array}$ & 1.28 (1.07 to 1.53$)$ & $1.48(1.11$ to 1.98$)$ & $1.66(0.97$ to 2.85$)$ \\
\hline $\begin{array}{l}\text { Severely food } \\
\text { insecure }\end{array}$ & $1.42(1.11$ to 1.79$)$ & 1.63 (1.18 to 2.24$)$ & 2.86 (1.72 to 4.74$)$ \\
\hline \multicolumn{4}{|c|}{ 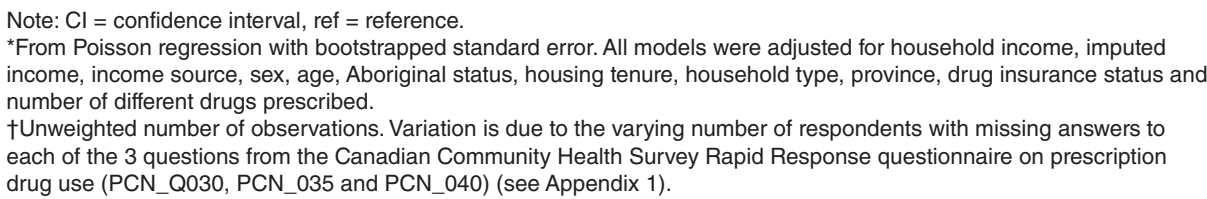 } \\
\hline
\end{tabular}

documented among Canadian adults substantial overlap between food insecurity and cost-related nonadherence and a graded association between the two. Having drug insurance lowered the probability of cost-related nonadherence, but the persisting association between food insecurity and nonadherence among insured adults suggests that the cost-sharing structure of existing insurance plans may pose financial barriers to drug adherence, particularly for food-insecure households. Our findings further suggest that cost-related nonadherence may be on the pathway connecting food insecurity to poor health. Our observation that adults experiencing severe food insecurity tended to report nonadherence to drugs for chronic conditions was consistent with evidence of poorer disease management among food-insecure adults. ${ }^{7-10}$ Medication nonadherence has been associated with heightened risk of hospital admission and death among patients with diabetes. ${ }^{28}$ The associations we found between food insecurity and worsening health and increased use of health care services are also consistent with prior work linking food insecurity to adverse health outcomes. ${ }^{11-13}$ The concurrence of food insecurity with cost-related nonadherence can only compound the health ramifications of either factor alone.

Both food insecurity and cost-related nonadherence are a function of limited resources; accordingly, policies that increase disposable income may help mitigate both issues. In the US, participation in the public health insurance program (Medicaid) and public nutrition program (Supplemental Nutrition Assistance Program) has been associated with less cost-related nonadherence and food insecurity, ${ }^{16,29,30}$ likely by freeing up disposable income as out-of-pocket expenses on health care or food were lowered. In Canada, studies have shown reductions in food insecurity following policy interventions that increased income for low-income households. ${ }^{31-34}$
Reducing out-of-pocket drug expenses is another way to improve adherence. Our results lend support to calls for a national pharmacare program, which could potentially reduce prevalence of cost-related nonadherence by providing universal prescription insurance. ${ }^{35-37}$ However, as suggested by our finding that $564(6.3 \%)$ of the 8943 insured adults in our sample reported cost-related nonadherence, the extent to which insurance mitigates cost-related nonadherence depends on the out-of-pocket expenditures required. The dose-response relation between food insecurity and cost-related nonadherence that we found suggests the need for greater reduction even exemption - of out-of-pocket drug expenses among those experiencing more severe food insecurity. Copayment exemption in private drug insurance was found to reduce cost-related nonadherence in a US sample. ${ }^{38}$ Lowering or waiving the out-of-pocket expenses for prescriptions may help reduce nonadherence for those with and without insurance in Canada, especially among food-insecure households, with potential positive impact on public health and the health care system. ${ }^{39}$

\section{Limitations}

Our cost-related nonadherence outcome was conditional on having a prescription, which may be subject to negative selection of patients avoiding physician encounters for reasons related to food insecurity. For instance, people with no prescription drug insurance are less likely to visit doctors than their insured counterparts, especially if they have chronic conditions. ${ }^{40}$ This may result from expectation of unaffordable prescriptions and associated shame. ${ }^{40}$ In that respect, our estimates should be regarded as conservative. Also, our survey data were cross-sectional, which limited our ability to ascertain causality. Unobserved factors such as 
income instability may have simultaneously driven food insecurity, cost-related nonadherence and poor health. Moreover, our data did not distinguish prescriptions for essential drugs of therapeutic importance from nonessential ones primarily for symptom alleviation. ${ }^{14}$ Adherence to nonessential drugs is more sensitive to price changes than adherence to essential drugs but is less impactful on one's health. ${ }^{41}$ Future endeavours may compare adherence to different types of drugs in relation to food insecurity to better understand vulnerable households' coping strategies. In addition, costrelated nonadherence was never assessed in the territories, and we had to exclude Ontario and Newfoundland and Labrador because of their failure to measure food insecurity. Our findings may not apply to these missing jurisdictions. Last, our outcomes were all self-reported and, thus, subject to response bias, and covariates such as insurance were also likely underreported. ${ }^{42}$ Since decisions around drug adherence are usually simultaneously driven by multiple factors,${ }^{14,15}$ some respondents may have downplayed the importance of cost because of social undesirability. We therefore regard our estimates as an underestimate.

\section{Conclusion}

We found household food insecurity to be positively associated with cost-related medication nonadherence. We also found increases in self-perceived health impacts of costrelated nonadherence among severely food-insecure nonadherents. Policies that increase disposable income for low-resourced households may attenuate cost-related nonadherence and food insecurity simultaneously. Expanding insurance coverage and adopting a more progressive insurance cost-sharing structure may reduce out-of-pocket prescription costs and associated nonadherence. The linkage between out-of-pocket drug expense and food insecurity needs further investigation, but lower out-of-pocket spending on prescriptions would likely reduce the health burden of food insecurity by fostering medication adherence and disease management.

\section{References}

1. Clement FM, Soril LJJ, Emery H, et al. Canadian publicly funded prescription drug plans: expenditures and an overview of patient impacts - prepared for Alberta Health. Calgary: Health Economics Group and Health Technology Assessment Unit, O'Brien Institute for Public Health, Interdisciplinary Chronic Disease Collaboration, School of Public Policy, University of Calgary; 2016.

2. Kapur V, Basu K. Drug coverage in Canada: Who is at risk? Health Policy 2005; 71:181-93.

3. Phillips K. Catastropbic drug coverage in Canada. Ottawa: Library of Parliament; 2016.

4. Sutherland G, Dinh T. Understanding the gap: a pan-Canadian analysis of prescription drug insurance coverage [report]. Ottawa: Conference Board of Canada; 2017.

5. Law MR, Cheng L, Kolhatkar A, et al. The consequences of patient charges for prescription drugs in Canada: a cross-sectional survey. CMA7 Open 2018;6: E63-70.

6. Tarasuk V, Mitchell A, Dachner N. Household food insecurity in Canada, 2012. Toronto: Research to Identify Policy Options to Reduce Food Insecurity (PROOF); 2014.

7. Tarasuk V, Mitchell A, McLaren L, et al. Chronic physical and mental health conditions among adults may increase vulnerability to household food insecurity. 7 Nutr 2013;143:1785-93.

8. Gucciardi E, Vahabi M, Norris N, et al. The intersection between food insecurity and diabetes: a review. Curr Nutr Rep 2014;3:324-32.
9. Anema A, Chan K, Chen Y, et al. Relationship between food insecurity and mortality among HIV-positive injection drug users receiving antiretroviral therapy in British Columbia, Canada. PLoS One 2013;8:e61277.

10. Cox J, Hamelin AM, McLinden T, et al.; Canadian Co-infection Cohort Investigators. Food insecurity in HIV-hepatitis $\mathrm{C}$ virus co-infected individuals in Canada: the importance of co-morbidities. AIDS Behav 2017;21:792-802.

11. Tarasuk V, Cheng J, Gundersen C, et al. The relation between food insecurity and mental health service utilization in Ontario. Can 7 Psychiatry 2018;63: 557-69.

12. Fitzpatrick T, Rosella LC, Calzavara A, et al. Looking beyond income and education: socioeconomic status gradients among future high-cost users of health care. Am 7 Prev Med 2015;49:161-71.

13. Gundersen C, Tarasuk V, Cheng L, et al. Food insecurity status and mortality among adults in Ontario, Canada. PLoS One 2018;13:e0202642.

14. Piette JD, Heisler M, Horne R, et al. A conceptually based approach to understanding chronically ill patients' responses to medication cost pressures. Soc Sci Med 2006;62:846-57.

15. Goldsmith LJ, Kolhatkar A, Popowich D, et al. Understanding the patient experience of cost-related non-adherence to prescription medications through typology development and application. Soc Sci Med 2017;194:51-9.

16. Berkowitz SA, Seligman HK, Choudhry NK. Treat or eat: food insecurity, cost-related medication underuse, and unmet needs. Am 7 Med 2014;127:303310.e3.

17. Loopstra R, Tarasuk V. What does increasing severity of food insecurity indicate for food insecure families? Relationship between severity of food insecurity and indicators of material hardship and constrained food purchasing. 7 Hunger Environ Nutr 2013;8:337-49.

18. Tarasuk V, Fafard St-Germain AA, Loopstra R. The relationship between food banks and food insecurity: insights from Canada. Voluntas 2019. doi: 10.1007/ s11266-019-00092-w.

19. Bartfeld J, Collins JM. Food insecurity, financial shocks, and financial coping strategies among households with elementary school children in Wisconsin. 7 Consum Aff 2017;51:519-48.

20. Nielsen R, Garasky S, Chatterjee S. Food insecurity and out-of-pocket medical expenditures: Competing basic needs? Fam Consum Sci Res 7 2010;39:137-51.

21. Herman D, Afulani P, Coleman-Jensen A, et al. Food insecurity and costrelated medication underuse among nonelderly adults in a nationally representative sample. Am 7 Public Health 2015;105:e48-59.

22. Afulani P, Herman D, Coleman-Jensen A, et al. Food insecurity and health outcomes among older adults: the role of cost-related medication underuse. 7 Nutr Gerontol Geriatr 2015;34:319-42.

23. Canadian Community Health Survey - Annual Component (CCHS). Rapid Response on prescriptions (cost-related non-adherence). Ottawa: Statistics Canada; 2017.

24. Law MR, Cheng L, Dhalla IA, et al. The effect of cost on adherence to prescription medications in Canada. CMA7 2012;184:297-302.

25. Tarasuk V, Fafard St-Germain AA, Mitchell A. Geographic and sociodemographic predictors of household food insecurity in Canada, 2011-12. BMC Public Health 2019;19:12.

26. Matheson J, McIntyre L. Women respondents report higher household food insecurity than do men in similar Canadian households. Public Health Nutr 2014;17:40-8.

27. Grant BF, Stinson FS, Dawson DA, et al. Prevalence and co-occurrence of substance use disorders and independent mood and anxiety disorders: results from the National Epidemiologic Survey on Alcohol and Related Conditions. Arch Gen Psychiatry 2004;61:807-16.

28. Ho PM, Rumsfeld JS, Masoudi FA, et al. Effect of medication nonadherence on hospitalization and mortality among patients with diabetes mellitus. Arch Intern Med 2006;166:1836-41.

29. Pooler JA, Srinivasan M. Association between Supplemental Nutrition Assistance Program participation and cost-related medication nonadherence among older adults with diabetes. FAMA Intern Med 2019;179:63-70.

30. Srinivasan M, Pooler JA. Cost-related medication nonadherence for older adults participating in SNAP, 2013-2015. Am 7 Public Health 2018;108:224-30.

31. McIntyre L, Dutton DJ, Kwok C, et al. Reduction of food insecurity in lowincome Canadian seniors as a likely impact of a guaranteed annual income. Can Public Policy 2016;42:274-86.

32. Loopstra R, Dachner N, Tarasuk V. An exploration of the unprecedented decline in the prevalence of household food insecurity in Newfoundland and Labrador, 2007-2012. Can Public Policy 2015;41:191-206.

33. Li N, Dachner N, Tarasuk V. The impact of changes in social policies on household food insecurity in British Columbia, 2005-2012. Prev Med 2016;93: 151-8.

34. Tarasuk V, Li N, Dachner N, et al. Household food nsecurity in Ontario during a period of poverty reduction, 2005-2014. Can Public Policy 2019;45:93-104.

35. Morgan SG, Boothe K. Universal prescription drug coverage in Canada: longpromised yet undelivered. Healthc Manage Forum 2016;29:247-54.

36. Brandt J, Shearer B, Morgan SG. Prescription drug coverage in Canada: a review of the economic, policy and political considerations for universal pharmacare. 7 Pharm Policy Pract 2018;11:28.

37. Wang C, Li Q, Sweetman A, et al. Mandatory universal drug plan, access to health care and health: evidence from Canada. F Health Econ 2015;44:80-96. 
38. Choudhry NK, Avorn J, Glynn RJ, et al.; Post-Myocardial Infarction Free Rx Event and Economic Evaluation (MI FREEE) Trial. Full coverage for preventive medications after myocardial infarction. N Engl 7 Med 2011;365:2088-97.

39. Tang KL, Ghali WA, Manns BJ. Addressing cost-related barriers to prescription drug use in Canada. CMA7 2014;186:276-80.

40. Allin S, Hurley J. Inequity in publicly funded physician care: What is the role of private prescription drug insurance? Health Econ 2009;18:1218-32.

41. Soumerai SB, Avorn J, Ross-Degnan D, et al. Payment restrictions for prescription drugs under Medicaid. N Engl f Med 1987;317:550-6.

42. Grootendorst P, Newman EC, Levine MA. Validity of self-reported prescription drug insurance coverage. Health Rep 2003;14:35-46.

Affiliations: Department of Nutritional Sciences (Men, Tarasuk), University of Toronto, Toronto, Ont.; Department of Agricultural and Consumer Economics (Gundersen), University of Illinois, Urbana, Ill.; Department of Community Health Sciences (Urquia), University of Manitoba, Winnipeg, Man.; Dalla Lana School of Public Health (Urquia), University of Toronto, Toronto, Ont.

Contributors: Valerie Tarasuk and Fei Men conceived and designed the study. Fei Men analyzed the data and drafted the manuscript. All of the authors contributed to data interpretation, critically revised the manuscript for important intellectual content, approved the final version to be published and agreed to act as guarantors of the work.

Funding: This study was supported by Canadian Institutes of Health Research grant PJT 153260 awarded to Valerie Tarasuk and Marcelo Urquia.
Data sharing: Data from this study cannot be shared publicly owing to the confidentiality agreement between Statistics Canada and respondents of the Canadian Community Health Survey. Data are available from the Statistics Canada Research Data Centre (telephone 905-525-9140 ext. 23661) for researchers who meet the criteria for access to confidential data.

Acknowledgements: The analysis presented in this paper was conducted at the Statistics Canada Research Data Centre at the University of Toronto, which is part of the Canadian Research Data Centre Network. The services and activities provided by the Research Data Centre are made possible by the financial or in-kind support of the Social Sciences and Humanities Research Council of Canada, the Canadian Institutes of Health Research, the Canada Foundation for Innovation, Statistics Canada and the University of Toronto. The authors thank the Research Data Centre staff for facilitating access to the Canadian Community Health Survey data.

Disclaimer: The funder and the Canadian Research Data Centre Network (CRDCN) had no role in the design and conduct of the study; collection, management, analysis and interpretation of data; or preparation, review, decision to submit for publication or approval of the manuscript. The views expressed in this paper are those of the authors and do not necessarily represent the funder's, CRDCN's or their partners'.

Supplemental information: For reviewer comments and the original submission of this manuscript, please see www.cmajopen.ca/content/7/3/ E590/suppl/DC1. 